\title{
Contratos psicológicos: uma revisão da
}

\section{literatura}

\author{
Leticia Fantinato Menegon \\ Tania Casado
}

\begin{abstract}
No presente trabalho tem-se por objetivo discutir, por meio de uma revisão da literatura, o conceito de contratos psicológicos e sua importância para o entendimento das relações de trabalho, apresentando seu conteúdo, categorização, principais correntes e resultados encontrados nas pesquisas nacionais e internacionais, para, em seguida, apresentar os desafios a serem explorados por futuros pesquisadores sobre o tema.
\end{abstract}

Palavras-chave: contrato psicológico, ruptura e violação do contrato psicológico, desafios de pesquisa.

\section{INTRODUÇÃO}

As transformações nos campos social, político, econômico e tecnológico trouxeram implicações legais e sociais importantes para a natureza das relações de trabalho (RUBERY et al., 2002), provocando consequências na forma como indivíduos se envolvem nessa nova estrutura. Os contratos de trabalho formais deixam de ser apropriados, porque a nova relação de trabalho se torna mais dinâmica. Contratos mais individualizados com as organizações passam a vigorar, deixando para trás a lógica dos contratos permanentes de emprego, que na maioria das vezes eram coletivos (GUEST, 1998). Isso impacta diretamente, dentre outros assuntos, o comportamento organizacional.

Os contratos psicológicos surgem como uma alternativa à gestão das relações tradicionais de trabalho, bem como uma resposta às novas configurações organizacionais, porque ajudam a descrever e a entender as mudanças vividas na relação empregador e empregado (ARNOLD, 1996; COYLE-SHAPIRO e KESSLER, 2000).

Para Shore e Tetrick (1994), o contrato psicológico promove a redução da insegurança na relação de trabalho porque nem todos os seus aspectos são abrangidos pelos contratos formais. Já Conway e Briner (2005) argumentam que:

- na discussão dos contratos psicológicos há um foco claro no relacionamento empregador-empregado. Atualmente, as abordagens tratam esse comporta-
Recebido em 02/setembro/2011

Aprovado em 28/novembro/2011

Sistema de Avaliação: Double Blind Review Editor Científico: Nicolau Reinhard

DOI: 10.5700/rausp1059
Leticia Fantinato Menegon, Bacharel em Administração pela Escola de Administração de Empresas de São Paulo da Fundação Getulio Vargas, Mestre e Doutora em Administração pela Faculdade de Economia, Administração e Contabilidade da Universidade de São Paulo, é Professora da Escola de Administração de Empresas de São Paulo da Fundação Getulio Vargas (CEP 01332-000 - São Paulo/SP, Brasil), da Universidade Presbiteriana Mackenzie, da Escola Superior de Propaganda e Marketing (ESPM). E-mail: leticia.menegon@fgv.br

Endereço:

Fundação Getulio Vargas EAESP

Rua Itapeva, $474-11^{\circ}$ andar

01332-000 - São Paulo - SP

Tania Casado, Psicóloga, Mestre e Doutora em Administração, é Professora do Departamento de Administração e Coordenadora do Centro de Carreiras da Faculdade de Economia, Administração e Contabilidade da Universidade de São Paulo (CEP 05508-010 - São Paulo/SP, Brasil).

E-mail: tcasado@usp.br 
mento como uma simples relação de causa e efeito, na qual indivíduos reagem aos vários estímulos da organização;

- a corrente de contratos psicológicos trata a relação empregatícia sob o ângulo da troca, já que os trabalhos acadêmicos "frequentemente enxergam o comportamento em termos de causa e efeito, em vez de processo, colocando o empregado em uma posição passiva, simplesmente reagindo às várias características do contexto" (CONWAY e BRINER, 2005, p.2).

Em vista da importância do tema contratos psicológicos, sua construção e discussão ganharam força no final da década de 1980 com o trabalho de Rousseau (1989). Grande parte dos trabalhos acadêmicos desenvolvidos pelos pesquisadores focou dois pontos principais sobre o tema, que são: o levantamento do conteúdo dos contratos psicológicos e sua categorização, e seus efeitos sobre o comportamento dos indivíduos no trabalho, principalmente no que se refere à ruptura desse contrato (ROBINSON e ROUSSEAU, 1994; ROBINSON e MORRISON, 1995; ROBINSON, 1996; COYLE-SHAPIRO e KESSLER, 2000; MENEGON, 2004; entre inúmeros outros).

Entretanto, de acordo com as leituras realizadas sobre o tema, entre eles Meckler, Drake e Levinson (2003), Raja, Johns e Ntalianis (2004), Conway e Briner (2005), e DelCampo (2007), poucos estudos têm examinado os antecedentes da formação e ruptura dos contratos psicológicos, entre outros inúmeros temas que se mostram relevantes para o avanço das pesquisas nesse campo de conhecimento.

Nesse sentido, o objetivo neste trabalho é discutir, por meio de uma revisão da literatura, o conceito de contrato psicológico e sua importância para o entendimento das relações de trabalho; apresentar o conteúdo desses contratos e sua categorização nas pesquisas internacionais; apresentar as principais correntes de pesquisas internacionais e brasileira e seus principais resultados; indicar os principais desafios a serem explorados por pesquisadores.

\section{O QUE É CONTRATO PSICOLÓGICO}

O conceito de contratos psicológicos é antigo e sua utilização em pesquisas organizacionais tem ganhado expressão, principalmente a partir do trabalho seminal de Denise Rousseau em 1989. Entretanto, sabe-se que os trabalhos produzidos anteriormente (MENNINGER, 1958; ARGYRIS, 1960; LEVINSON et al., 1963; SCHEIN, 1965/1980) impulsionam as discussões mais recentes. Esses trabalhos, apesar de se referirem ao mesmo conceito, utilizavam-no para descrever diferentes fenômenos, como é possível observar nas definições que seguem.

"Na medida em que os gestores percebem que os empregados tenderão a produzir de forma ótima sob liderança passiva, e desde que os empregados concordem, é possível que a relação entre gestores e empregados possa ser chamada de contrato psicológico. O empregado manterá alta produção, baixo ressentimento etc., se o gestor garantir e respeitar as normas da cultura informal dos empregados. Isto é precisamente o que os empregados precisam” (ARGYRIS, 1960, p.97).

"As expectativas dos empregados e da companhia eram concebidas como componentes do contrato psicológico. Tal contrato é raramente formal. É uma concepção mais ampla do que o uso tradicional da palavra na relação empresarial, na qual significou acordos legais escritos entre gestores e empregados. O contrato psicológico é uma série de expectativas mútuas das quais as partes da relação podem não estar cientes, mas que regem as relações de uns com os outros" (LEVINSON et al., 1963, p.21).

Os trabalhos que mais influenciaram uma parte da comunidade acadêmica atual sobre o conceito de contrato psicológico foram os de Levinson et al. (1963) e Schein (1965/1980). Ambos partiram da ideia central de que tais contratos compõem as expectativas mútuas entre indivíduos e organizações e que estão fortemente calcados na percepção de troca na relação de trabalho. Tal legado foi seguido por diferentes autores. A seguir, estão expressos os conceitos propostos por alguns deles.

"Um contrato implícito entre um indivíduo e sua organização, que especifica o que cada um espera dar e receber na relação" (KOTTER, 1973, p.92).

"O contrato psicológico é definido como um conjunto de expectativas entre o indivíduo e a organização" (HERRIOT, 1995, p.1).

Como é possível observar a partir dessas definições, forma-se uma corrente acadêmica fortemente pautada na ideia de que os contratos psicológicos, para existirem, dependem dos pilares expectativa e mutualidade. Essa corrente de pensamento tem sido bastante criticada por aqueles que seguem a segunda corrente de definição dos contratos psicológicos, liderada por Rousseau (1989; 1990; 1995), Rousseau e Parks (1993), Robinson (1996), Herriot e Pemberton (1997), Morrison e Robinson (1997), entre outros.

De acordo com Rousseau (1989, p.123),

"o termo contrato psicológico refere-se a uma crença individual independentemente dos termos e condições de um acordo de troca recíproco entre a pessoa focal e a outra parte. A questão-chave aqui inclui a crença de que uma promessa foi feita e uma contrapartida oferecida em troca, ligando as partes a alguns conjuntos de obrigações recíprocas".

Refere-se também às 
“percepções de ambas as partes da relação de trabalho, organização e indivíduo, sobre as obrigações implícitas à relação" (HERRIOT e PEMBERTON, 1997, p.45).

\section{Trata-se de}

"uma crença do empregado a respeito das obrigações recíprocas entre empregador e empregado, sendo que estas obrigações estão baseadas na percepção de promessa e não são necessariamente reconhecidas pelos agentes da organização" (MORRISON e ROBINSON, 1997, p.229).

Os principais pilares dessas definições, que significaram um divisor de águas na conceituação dos contratos psicológicos, liderados por Rousseau (1989), são o caráter promissório e o foco no nível individual na formação do contrato, pois o contrato psicológico está nos olhos de quem o vê.

As promessas tornaram-se o termo preferido por muitos autores (representantes da segunda corrente) ao definirem contratos psicológicos, pois, de acordo com Conway e Briner (2005), elas parecem ser mais contratuais, enquanto expectativas parecem ter um significado mais genérico e, ao mesmo tempo, somente fazem parte do contrato psicológico quando estão baseadas em uma promessa percebida. Ao visitar a definição de expectativa e promessa, é possível perceber as diferenças conceituais entre os termos que, por sua vez, implicam uma diferenciação do conceito de contrato psicológico.

Promessas, segundo Rousseau e Parks (1993), referem-se ao comprometimento de fazer algo. É a garantia de que algo será feito. Essa garantia, por sua vez, gera a obrigação de cumprimento da promessa que, se não for realizada, produz "uma resposta mais intensa do que aquela gerada pela não realização das expectativas" (COYLE-SHAPIRO e KESSLER, 2000, p.906). Como expressa Rousseau (1989, p.128),

"a incapacidade de cumprir os termos de um contrato psicológico produz mais do que expectativas não satisfeitas. Sinaliza danos ao relacionamento entre a organização e o indivíduo. Subjacente a um contrato psicológico está a confiança, que se desenvolve a partir de uma crença de que as contribuições serão recíprocas e de que existe uma relação em que as ações de uma parte estão vinculadas às da outra. "Um dano em uma relação não é facilmente restaurado"”.

Expectativas, por sua vez, são "uma crença momentânea a respeito da probabilidade de que uma ação em particular será seguida de um resultado particular" (VROOM, 1964, p.17). Em outras palavras, estão baseadas em uma crença provável a respeito de um futuro evento. A palavra central nesse caso é a probabilidade. De acordo com Rousseau e Parks (1993), enquanto todas as promessas envolvem expectativas, estas últimas não necessariamente envolvem um elemento promissório.
De acordo com a análise de Conway e Briner (2005), promessas estão enraizadas em um contrato e seus participantes esperam que este seja realizado simplesmente pelo fato de uma das partes ter comunicado ou se comportado de determinada maneira, de modo a permitir que a outra acredite que uma promessa tenha sido feita. Expectativas, como aquelas baseadas em crenças prováveis, são normalmente constantes e, de alguma forma, dispositivos estáveis de nossa experiência consciente. Os seres humanos geralmente tendem a esperar que algumas coisas tenham maior probabilidade de acontecer em detrimento de outras. Entretanto, quando um indivíduo acredita que uma promessa tenha sido feita, tende a antecipar a garantia de que tais promessas serão cumpridas, agindo de modo a checar se a promessa foi ou não feita, planejando o que será feito assim que ela for realizada e, principalmente, buscando meios para cumprir a contrapartida do contrato. Em outras palavras, o indivíduo que acredita em uma promessa não trabalha com probabilidades, mas sim com fatos concretos (CONWAY e BRINER, 2005).

Nesse sentido, o trabalho de Rousseau (1989) foi um marco na discussão do tema contratos psicológicos, porque contribuiu de forma substancial para a elaboração do construto. Entendendo que contratos, escritos ou não, estão sujeitos a diferentes percepções acerca da mensagem em si, por considerar que a forma como as mensagens são expressas pode estar fragmentada, ou ainda que estejam sujeitas aos limites cognitivos, aos diferentes referenciais individuais e sociais e à própria complexidade das interações sociais, a autora afirma que a subjetividade é um fator extremamente relevante na discussão de qualquer contrato estabelecido entre diferentes partes. Tal subjetividade advém do próprio contexto socioeconômico vivido pela sociedade, conforme explicita MacNeil (1985, p.62):

"Tendências na Lei parecem suportar a execução de acordos não explícitos ou implícitos, reconhecendo que os relacionamentos estão se tornando a forma dominante da atividade econômica e planejamento da sociedade moderna".

A existência de subjetividade nas relações contratuais torna importante a discussão de seu papel nas relações de trabalho. Segundo MacNeil (1985), a subjetividade dos contratos na perspectiva de cada uma das partes implica que todos os contratos, escritos ou não, são fundamentalmente psicológicos e, por isso, estão no olhar de quem os vê. A partir desse entendimento é que Rousseau define os contratos psicológicos como

"uma crença individual independente dos termos e condições de troca estabelecida entre uma pessoa focal e a outra parte. A questão-chave aqui inclui a crença de que uma promessa foi feita e uma contrapartida foi oferecida em troca, ligando as partes em um conjunto de obrigações recíprocas" (ROUSSEAU, 1989, p.123). 
De acordo com Rosseau (1989), quando um indivíduo percebe que suas contribuições geram uma obrigação de reciprocidade por parte da organização, o contrato psicológico emerge. Acreditar que a reciprocidade ocorrerá pode ser um precursor do desenvolvimento do contrato psicológico, porque é a crença do indivíduo na obrigação de reciprocidade que o constitui. É importante salientar que essa crença é unilateral porque, conforme expresso anteriormente, o contrato está no olhar de quem o vê e, por isso, é subjetivo.

Arnold (1996), Guest (1998) e Conway e Briner (2005) criticam o posicionamento de Rousseau quanto à questão da uniteralidade (ou não existência de mutualidade) e subjetividade do conceito contrato psicológico. Para esses autores, assim como os contratos legais somente são estabelecidos entre duas partes e com o consentimento delas e, por isso, são mútuos, os contratos psicológicos, na definição de Rousseau, estão sujeitos à arbitrariedade. Ao considerar que esse contrato está nos olhos de quem o vê, cada parte do contrato acredita que haja um acordo, mas não há necessidade de haver um real acordo em que as partes tenham o mesmo entendimento do contrato. Os contra-argumentos à critica surgem, como expressam Robinson e Rousseau (1994, p.246):

"Nota-se que são crenças ou percepções relativas a promessas ou aceitação. Cada uma das partes considera que ambas as partes fizeram promessas e que ambas as partes aceitaram as mesmas condições contratuais. Contudo, isso não significa que ambas as partes necessariamente compartilham de um mesmo entendimento das cláusulas contratuais. Cada uma das partes só acredita que partilham da mesma interpretação do contrato".

MacNeil (1985) reforça tal argumentação ao dizer que todos os contratos, escritos ou não, são essencialmente subjetivos porque seus termos estão sujeitos à interpretação subjetiva de cada indivíduo.

Rousseau (1998) afirma que a interpretação de Arnold (1996), Guest (1998) e Conway e Briner (2005), ao dizerem que o conceito de contrato psicológico definido por ela não considera os aspectos de mutualidade, está incorreta. Para a autora, a questão-chave acerca desse tema é que a percepção de mutualidade e não a mutualidade de fato é que permite o surgimento do contrato psicológico (ROUSSEAU, 1995; 1998).

Guest (1998) e Conway e Briner (2005) vão mais longe com as críticas em relação ao trabalho desenvolvido por Rousseau. Conway e Briner (2005) expõem que o contrato psicológico é uma questão de troca. Em outras palavras, refere-se a um acordo de troca percebido entre as partes, em que a reciprocidade precisa ocorrer. Se essa reciprocidade não ocorre, ela descaracteriza o contrato. Nesse sentido, os autores questionam a validade do contrato psicológico como contrato. Rousseau (1998), sete anos antes já havia respondido a esse questionamento, assim como MacNeil (1985), quando afirmam que todos os contratos legais são fundamentalmente psicológicos. A reciprocidade ocorre no campo da percepção de obrigação de reciprocidade, o que não implica necessariamente uma reciprocidade de fato. Se não fosse assim, o contrato psicológico não se diferenciaria do contrato na forma legal, que, "na lei, cria e define direitos e obrigações a serem implementados entre as partes que intencionalmente criaram um relacionamento" (SPINDLER, 1994, p.326). É importante lembrar que, sob a definição de Rousseau (1989), o contrato psicológico ocorre exclusivamente no nível individual, e não no nível relacional.

Outro aspecto criticado por Guest (1998) e Conway e Briner $(2005)$ refere-se às partes desse contrato. Segundo Guest (1998, p.652),

"o contrato de trabalho será assinado entre o empregado e um agente da organização. O contrato psicológico enfrenta a frequentemente citada dificuldade de definir o que de fato a organização quer dizer. Rousseau (1995) dedica algum espaço para a análise dos 'agentes', mas não para contornar o problema, simplesmente porque existem múltiplos agentes na organização e eles podem oferecer diferentes e, por vezes, contratos concorrentes".

Conway e Briner (2005) reiteram a discussão, perguntando quem representa a organização ou o empregador na contratação psicológica. Enquanto a maioria das definições enfatiza o empregado como o principal contratante do contrato psicológico, uma área de extenso debate preocupa-se se, de fato, a outra parte contratante, a organização, pode ou possui um contrato psicológico (CONWAY e BRINER, 2005).

A conceituação clássica sobre o tema (ARGYRIS, 1960; LEVINSON et al., 1963; SCHEIN, 1965/1980) e algumas das definições recentes (HERRIOT e PEMBERTON, 1997; COYLE-SHAPIRO e KESSLER, 1998; GUEST, 1998) consideram que a outra parte contratante é o empregador, representado por agentes, como gerentes de linha ou seniores, e por características de grupos ou organizações, como a cultura. Para Rousseau (1989), entidades abstratas não podem possuir contratos psicológicos. Apenas os representantes de organizações, ou agentes, poderiam tê-lo. Entretanto, conforme expõem Conway e Briner (2005), o problema-chave na posição de Rousseau é que as definições de contratos psicológicos estabelecem que empregados devem tratar a organização como se ela possuísse um contrato psicológico.

Guest (1998) complementa dizendo que a solução do problema dos agentes adotada por Rousseau e outros pesquisadores contemporâneos acaba por antropomorfizar a organização, tornando-a um indivíduo e, assim, definindo o contrato psicológico somente em termos da percepção do empregado.

Segundo Rousseau (1989), as organizações tornam-se parte integrante do contrato psicológico por meio de seus representantes, que podem ser os proprietários ou mesmo representantes 
da organização. Ainda há de se considerarem os valores, as práticas organizacionais, as comunicações, entre outros. O que de fato ocorre é que indivíduos entram em contato com pessoas que lhes transmitem uma série de informações, mensagens, valores e o que o indivíduo percebe como promessa é que comporá o contrato psicológico. Então, pessoas, mensagens, práticas organizacionais etc. podem apenas ser caracterizadas como meios para a formação desse contrato e não como a outra parte contratante. Conforme explicado anteriormente, o contrato psicológico não equivale a um contrato legal. Ele é um produto que advém da interação social.

Muitas definições de contratos psicológicos consideram que as crenças de promessas percebidas são formadas ou moldadas pela interação entre o empregador e o empregado. Em outras palavras, as crenças formadas em outras relações de trabalho prévias não são consideradas parte desse contrato. Entretanto, segundo Conway e Briner (2005), pesquisadores discordam sobre a extensão em que o contrato psicológico é moldado por fatores externos ou internos à organização. Pelas definições clássicas de Levinson et al. (1963) e Schein (1965/1980), os contratos psicológicos são consideravelmente moldados por experiências que antecedem a relação entre empregador e empregado (LEVINSON et al., 1963). Entretanto, conceituações mais recentes, como as de Rousseau $(1989 ; 1995)$ e seus seguidores, dão menos ênfase à influência de experiências antecessoras na relação atual de trabalho e, por sua vez, na formação do contrato psicológico, e consideram que é da relação com a atual organização e seus agentes que esse contrato emerge. Contudo, Rousseau (1998) afirma que ninguém ainda pesquisou sobre as origens do contrato psicológico individual, e Conway e Briner (2005), sete anos depois, reafirmam tal posicionamento ao colocarem como desafio para os pesquisadores, dentre outros, responder de onde surgem os contratos psicológicos, quais são os fatores que influenciam tais contratos, quais aspectos inerentes ao indivíduo contribuem para sua formação.

Nesse sentido, Meckler, Drake e Levinson (2003) abrem um amplo debate sobre a omissão dos fundamentos teóricos da Psicologia nos trabalhos sobre contratos psicológicos, que para eles abrangem os mecanismos comportamentais do processo de contratação, como a teoria da agência, confiança e justiça para explicar as reações dos indivíduos na violação desse contrato. No entanto, tais discussões afastaram-se demais da Psicologia Clínica, campo de conhecimento base para o entendimento dos contratos psicológicos.

De acordo com o trabalho Putting psychology back into psychological contracts, Meckler, Drake e Levinson (2003) sugerem que o ambiente de trabalho é um espaço em que os empregados podem canalizar suas necessidades de afeto, agressão, dependência e, também, conquistar seu ideal de ego. Na medida em que os objetivos organizacionais e do empregado estejam razoavelmente alinhados, estes últimos estarão naturalmente motivados a trabalhar para preencher essas necessidades psicológicas.
A definição atual de contratos psicológicos, conforme discutido, está pautada em dois pilares básicos: o das expectativas e o das promessas. Expectativas são crenças momentâneas conscientes, assim como a percepção de uma promessa também é consciente, ainda que a percepção ou expectativa surja de um processo de interação social não escrito, mas entendido.

Segundo Meckler, Drake e Levinson (2003, p.218),

“embora a literatura contemporânea de contrato psicológico insista em falar principalmente sobre a consciência das expectativas [ou percepções] na relação empregatícia, o conceito clínico original centrou-se em compreender quais são as necessidades inconscientes de afeto, dependência e agressão, e da identidade pessoal ou ideais de ego que impulsionam a motivação e o comportamento humano".

A revisão realizada para este trabalho indica que as pesquisas atuais sobre o tema constroem erroneamente, bem como suprimem e/ou ignoram, as necessidades psicológicas relevantes para a discussão dos contratos psicológicos. Isso porque, talvez, muitos dos autores não entendam que os aspectos sociais e econômicos desses contratos diferem dos elementos psicológicos, conforme exemplificam Meckler, Drake e Levinson (2003, p.218):

"O aspecto social descreve comportamentos aceitáveis e inaceitáveis que podem ser utilizados para satisfazer necessidades psicológicas. Entretanto, um contrato social não é um acordo segundo o qual o trabalhador será colocado em situações que irão ajudá-lo a preencher essas necessidades. Componentes econômicos oferecem compensações que podem ajudar a satisfazer um desejo do empregado (um grande escritório, um bom salário, um importante título), mas não vai abranger outras questões que são fundamentais para a realização do ideal de ego do indivíduo ou outras necessidades psicológicas".

As necessidades citadas por Meckler, Drake e Levinson (2003) são em sua expressiva maioria inconscientes, possuem grande poder sobre as ações e as percepções dos indivíduos e são resultado parcial das idiossincrasias do nível individual. Tais idiossincrasias, bem como percepções individuais, sequer são relacionadas à personalidade dos indivíduos quando o assunto é contrato psicológico.

O trabalho de Rousseau (1995) discute, breve e superficialmente, a inconsciência ao tratar esses contratos quando aborda as estruturas ou modelos mentais de Foa e Foa (1974). Para essas últimas, o entendimento humano sempre passa pelo filtro das estruturas mentais individuais, que permitem que cada um entenda determinada informação ou conhecimento de uma maneira diferente, o que, por sua vez, torna a percepção do contrato psicológico algo estritamente individual. 
Raja, Johns e Ntalianis (2004), partindo da ausência de trabalhos científicos que relacionem personalidade e contratos psicológicos, examinam a relação entre a personalidade do empregado e o tipo de contrato psicológico, a percepção de ruptura de contrato e sentimento de ruptura desse contrato. Apesar de trazer resultados bastante significativos no que se refere ao impacto da personalidade nesses contratos, os autores não entram na discussão sobre os aspectos inconscientes dos indivíduos. O mesmo faz DelCampo (2007) ao examinar o impacto das diferenças individuais em reportes de ruptura do contrato psicológico.

A ausência de uma ampla discussão das raízes da Psicologia nos trabalhos publicados sobre esse tipo de contrato contribui para a não identificação de seus antecedentes, bem como quais fatores e aspectos individuais contribuem em sua formação, questionamento proposto tanto por Rousseau (1998) quanto por Conway e Briner (2005).

\section{O CONTEÚDO E A CATEGORIZAÇÃO DOS CONTRATOS PSICOLÓGICOS}

Conforme mencionado na seção anterior, o contrato psicológico existe no nível individual, na forma de uma crença individual dos termos de troca de um relacionamento. Tais termos, ou conteúdo desse contrato, expressam o que os indivíduos acreditam que lhes foi prometido, e que promessas fizeram a seu empregador. Segundo Conway e Briner (2005, p.37):

"É importante notar que o conteúdo do contrato psicológico não é o que o empregado de fato dá e recebe de seu empregador, na verdade são as promessas explícitas e implícitas [percebidas] em torno da troca".

Apesar de as pesquisas sobre o conteúdo desse tipo de contrato serem as mais numerosas depois do tema ruptura dos contratos psicológicos, na verdade poucas têm sido conduzidas sobre ele.

Os trabalhos mais expressivos que tratam de seu conteúdo são de Rousseau (1990), Guzzo, Noonan e Elron (1994) e Herriot, Manning e Kidder (1997). Esses autores, no entanto, restringiram suas investigações de conteúdo para uma limitada cesta de promessas percebidas pelos empregados que consideraram mais importantes.

Rousseau (1990) gerou conteúdos de promessas a partir de uma pesquisa com 224 graduandos de um curso de MBA (Master of Business Administration) que tinham recentemente aceitado ofertas de trabalho. Eles foram questionados a respeito de suas percepções do processo de recrutamento/seleção, intenções e motivações. Como resultado, foram identificadas, segundo a visão dos alunos, as seguintes obrigações do empregador: promoção, alta remuneração, pagamento associado ao nível de desempenho, treinamento, segurança do trabalho, desenvolvimento na carreira e suporte para os problemas pessoais; $\mathrm{e}$ as seguintes obrigações do empregado: trabalhar horas-extras, lealdade, iniciativa para realizar tarefas não requeridas no trabalho, notificação adiantada quando aceitar emprego em outro lugar, disposição para aceitar transferências, recusa em oferecer suporte aos competidores do empregador, proteção em relação às informações sigilosas, trabalhar no mínimo dois anos na organização (ROUSSEAU, 1990).

Guzzo, Noonan e Elron (1994), em uma pesquisa com gestores expatriados, geraram 43 itens que deveriam representar $o$ conteúdo do contrato psicológico. Entretanto, os autores falharam ao trabalhar a medida que representaria esse contrato, pois não questionaram as promessas feitas pela organização, mas o que eles achavam que a organização deveria prover. Como notou Arnold (1996), o termo deveria não é consistente com a natureza promissória do contrato psicológico.

Conforme as palavras de Conway e Briner (2005), provavelmente o trabalho mais meticuloso a respeito do conteúdo dos contratos psicológicos tenha sido realizado por Herriot, Manning e Kidder (1997), que exploraram ambas as perspectivas, ou seja, a do empregado e a do empregador. Para capturarem a perspectiva do empregador, gestores da organização foram requisitados a falar sobre ela. A técnica utilizada para o estudo foi a do incidente crítico. A amostra trabalhada foi de 184 empregados e 184 gestores britânicos (representantes da organização). Alguns exemplos dos resultados encontrados, na perspectiva de empregados e gestores, respectivamente, são: justiça, atendimento das necessidades familiares, humanidade, reconhecimento entre outros; trabalhar as horas contratadas, fazer o trabalho com qualidade e quantidade; lealdade, flexibilidade, entre outros.

No Brasil, desenvolveu-se um trabalho de naturezas qualitativa e quantitativa, realizado com sete empregados de duas consultorias que se encontram entre as cinco maiores do mundo. O conteúdo do contrato psicológico levantado foi semelhante ao das pesquisas supracitadas, exceto: aceitação da diversidade, aprendizado intenso, exposição profissional, acesso (a poder, clientes, informações privilegiadas, por exemplo) e status social e profissional (MENEGON, 2004).

É importante notar que os estudos mencionados trabalham especificamente medidas de conteúdo individual, como escalas e termos representativos do contrato psicológico. Entretanto, essas não são as únicas medidas de conteúdo utilizadas nas pesquisas.

Segundo Rousseau e Tijoriwala (1998, p.685),

"as avaliações orientadas para conteúdo endereçam os termos e obrigações recíprocas que caracterizam um contrato psicológico individual. [...] As avaliações de conteúdo diferem se elas focam as partes do contrato psicológico (por exemplo, termos) ou um composto mais amplo (por exemplo, caracterizações sumárias do conteúdo do contrato)".

As medidas quantitativas e padronizadas do conteúdo do contrato podem ser operacionalizadas de três maneiras: 
- termos - são as obrigações que os indivíduos percebem que devem (por exemplo, trabalho duro, aceite de transferência) e seus empregadores devem em retorno (por exemplo, promoção, suporte a problemas pessoais) (ROUSSEAU e TIJORIWALA, 1998);

- composto de termos - "compostos são evidenciados como medidas sintetizadas do conteúdo de um contrato global baseadas numa escala de termos contratuais individuais" (ROUSSEAU e TIJORIWALA, 1998, p.686-687);

- classificação nominal - são tipologias pelas quais os respondentes indicam qual categoria reflete seu entendimento a respeito de uma relação empregatícia. Por serem altamente subjetivos e específicos para cada indivíduo, os contratos psicológicos podem referir-se a elementos concretos (pagamento, condições de trabalho) e abstratos (segurança, desafios) que são interpretados, no plano individual, pela relação que ocorre entre empregador e empregado (GUZZO e NOONAN, 1994).

Isso posto, faz sentido criar uma tipologia representativa de modo a possibilitar o levantamento do conteúdo do contrato psicológico.

A classificação nominal tem sido amplamente utilizada em pesquisas sobre contratos psicológicos (MILLWARD e HOPKINS, 1958; ROUSSEAU, 1990; ROUSSEAU e PARKS, 1993; ROUSSEAU, 2000; HUI, LEE e ROUSSEAU, 2004; RAJA, JOHNS e NTALIANIS, 2004; entre outros). Proposta inicialmente por MacNeil (1985), muitos acadêmicos desenvolveram e adotaram uma tipologia baseada nos contratos promissórios, representada pelos contratos transacionais e relacionais.

Os contratos psicológicos transacionais referem-se àqueles que são extraídos de termos de troca bem descritos. Conforme define Rousseau (2000, p.4),

“emprego com um regime de curto prazo com duração limitada, essencialmente centrado no intercâmbio econômico; deveres específicos e restritos, e envolvimento limitado do trabalhador na organização".

Os contratos psicológicos relacionais são menos definidos com base nos termos de troca. Para Rousseau (2000, p.4),

“emprego com regime de longo prazo com duração ilimitada, centrado em confiança e lealdade mútuas. Recompensas estão vagamente condicionadas ao desempenho, derivam de adesão e participação na organização".

Para Rousseau (1995), os termos dos contratos psicológicos podem ser pensados como extremos de um continuum.

Compreendidos quais conteúdos do contrato psicológico são trabalhados nas pesquisas e de que forma são operacionalizados, é de fundamental importância discutir o foco das pesquisas acadêmicas no mundo, que trata principalmente dos consequentes dos contratos psicológicos.

\subsection{As pesquisas em contratos psicológicos}

Atualmente, o tema mais trabalhado nas pesquisas sobre contrato psicológico no mundo é a ruptura e a grande massa produzida está nos Estados Unidos da América. Provavelmente, o grande interesse em torno do assunto ocorre porque esta é a forma de entender como esses contratos afetam os sentimentos, as atitudes e os comportamentos dos indivíduos no ambiente de trabalho.

Para Rousseau e Parks (1993), a ruptura do contrato psicológico ocorre quando o empregado percebe que a organização falha no preenchimento das obrigações desse contrato. Como sugere a definição, o oposto de ruptura é o preenchimento, atendimento do contrato.

Pesquisadores utilizaram as palavras ruptura e violação como sinônimos até quando Morrison e Robinson (1997) distinguiram formalmente os conceitos, distinção aceita atualmente. As autoras descrevem ruptura como uma comparação cognitiva entre o que foi recebido pelo indivíduo e o que foi prometido pela empresa, ou seja, a percepção de uma discrepância entre o que foi prometido e o que de fato o indivíduo recebeu. Violação, por outro lado, foi descrita como uma reação emocional ou afetiva intensa que pode acompanhar a ruptura.

A percepção de que uma promessa não foi preenchida pode gerar um processo de comparação pelo qual o empregado avalia o quanto cada uma das partes da relação de trabalho compareceu com suas obrigações. Se concluir que os resultados são desfavoráveis para ele, perceberá, então, uma ruptura do contrato. "Essa comparação está sujeita ao viés cognitivo e à determinação do limiar da ruptura" (PEYRAT-GUILLARD, 2008, p.483). Ao perceber a ruptura, o empregado estará sujeito a interpretar esse processo, que consiste na tentativa de dar sentido ao evento ocorrido. Dependendo do processo de interpretação, o indivíduo poderá insurgir-se contra a reação violação do contrato psicológico. Acredita-se que pelo fato de a ruptura dos contratos psicológicos promover consequências importantes para a organização, pesquisadores tenham concentrado seus esforços na investigação de como a ruptura afetaria os resultados do indivíduo perante a organização, ou seja, as consequências dela.

Diversos estudos (ROBINSON, KRAATZ e ROUSSEAU, 1994; ROBINSON e ROUSSEAU, 1994; ROBINSON e MORRISON, 1995; ROBINSON, 1996; COYLE-SHAPIRO e KESSLER, 2000; KICKUL, LESTER e FINK, 2002; LESTER et al., 2002) concluíram que a ruptura está relacionada a níveis mais baixos de bem-estar do indivíduo no trabalho; atitudes negativas perante o trabalho e a organização, como insatisfação no trabalho, baixo comprometimento organizacional, diminuição dos níveis de confiança e aumento da intenção de sair da organização; e comportamentos como baixo nível de cidadania organizacional, aumento da rotatividade voluntária, baixo desempenho. Esses resultados fornecem insumos importantes sobre como as organizações, havendo vontade de controlar tais consequências no ambiente organizacional, deveriam tratar o gerenciamento dos contratos psicológicos. 
Desde a distinção feita entre ruptura e violação por Morrison e Robinson (1997), muito se produziu sobre as consequências da ruptura, conforme apresentado anteriormente. Entretanto, como pontuam Conway e Briner (2005, p.65), "é notório que interesses em pesquisas sobre violação não se desenvolveram". O motivo mais provável deste desinteresse talvez esteja na facilidade de estudar variáveis extensamente trabalhadas e consolidadas na literatura de comportamento organizacional, como é o caso das consequências da ruptura do contrato psicológico; de acessar tais variáveis nos indivíduos ante as diversas medidas delas disponíveis na literatura acadêmica; e na dificuldade de trabalhar a violação, já que as reações à ruptura podem ser constrangedoras para o indivíduo, dificultando sua externalização, afinal podem trazer à tona suas fragilidades.

O estudo brasileiro realizado por Menegon (2004) apresentou algumas reações à ruptura que se caracterizaram como violação do contrato psicológico. Elas são expressas pelos termos: vingança, mágoa, depressão e alívio. Quatro anos mais tarde, Peyrat-Guillard (2008) realizou, na empresa francesa Michelin, um estudo que permitiu o levantamento de palavras que descrevessem as reações emocionais intensas, representando a violação. São elas: preocupação, raiva, ódio, amargura, ansiedade, revolta, traição e confusão. Observa-se que os estudos de Menegon e Peurat-Guillard convergem, indicando que, apesar de os estudos não estarem amplamente avançados nesse exato assunto, os poucos produzidos estão alinhados.

\section{ALERTAS E DESAFIOS AOS ESTUDIOSOS}

Conforme mencionado neste artigo, as principais pesquisas internacionais desenvolvidas focaram dois aspectos: o desenvolvimento da conceituação e a definição do conteúdo dos contratos psicológicos e estudos que investigam as consequências da ruptura desses contratos.

Com o objetivo de fortalecer as pesquisas sobre o tema, é de fundamental importância endereçar aos pesquisadores de contratos psicológicos, ante as pesquisas já realizadas, os diversos desafios que ainda não foram (ou pouco foram) trabalhados pelas pesquisas internacionais. Não se pretende abranger, com isso, a totalidade dos desafios, mas colocar em pauta questionamentos que ajudem a comunidade acadêmica a avançar em diversos campos da pesquisa pouco ou nada explorados.

Alguns desses desafios são apontados por Conway e Brinner (2005):

\section{- Desafio 1}

Qual é o conteúdo do contrato psicológico? Pesquisas atuais sobre o conteúdo desses contratos têm concentrado seus esforços nas promessas explícitas. Pouco se discute sobre o conteúdo dos contratos psicológicos implícitos e levantamentos nesse sentido são raros. Também não são considerados nas discussões sobre o conteúdo dos contratos psicológicos questionamentos como os apontados a seguir.
- Como experiências que antecedem a relação de um indivíduo com uma organização podem moldar o contrato psicológico?

- Como experiências fora da organização (por exemplo, circunstâncias familiares) podem moldar o contrato psicológico?

- Qual a importância relativa de fatores organizacionais, extraorganizacionais e pré-organizacionais na elaboração dos contratos psicológicos?

- Quando e como os conteúdos dos contratos psicológicos são negociados?

- Pouco se sabe como diferenças individuais (por exemplo, personalidade) ou fatores sociais afetam o conteúdo dos contratos psicológicos.

- O conteúdo do contrato psicológico afeta os resultados organizacionais? Se sim, como afeta?

\section{- Desafio 2}

A ruptura do contrato psicológico. As pesquisas recentes focam a relação causal entre ruptura do contrato psicológico e suas consequências no ambiente organizacional. Pouco se sabe com qual frequência elas ocorrem, se há diferenças expressivas entre as rupturas que ocorrem diária, mensal e anualmente. Também são inexistentes pesquisas que questionam quais fatores levam à ruptura, se alguns indivíduos estão mais propensos a vivenciar a ruptura do que outros, se certos contextos organizacionais são mais propensos à ruptura do que outros, como rupturas de diferentes tipos de contratos psicológicos afetam os resultados do indivíduo na organização. Ademais, é importante que as pesquisas, ao abordarem a ruptura, se interessem, também, pela violação dos contratos psicológicos, abrangendo as reações à ruptura e suas consequências para as organizações.

\section{- Desafio 3}

Pesquisando contratos psicológicos. A expressiva maioria das pesquisas internacionais utilizam self-report questionnaires para promover pesquisas sobre contratos psicológicos. Há uma necessidade urgente de utilização de outras metodologias que não envolvam tais questionários, pois neles consideram-se conteúdos e consequências de ruptura de contratos psicológicos já predeterminados, limitando a leitura de uma realidade densa e complexa. O uso de metodologias qualitativas são mais raras e necessárias para responder aos inúmeros questionamentos apontados neste artigo.

\section{CONCLUSÕES}

Neste trabalho, propôs-se a fazer uma revisão crítica da literatura, com o objetivo de apresentar ao leitor as discussões mais recentes sobre o conceito de contratos psicológicos, bem como apresentar os resultados das pesquisas internacionais e brasileiras sobre o tema. Em seguida, foram analisadas as principais 
lacunas existentes em tais pesquisas, com o maior objetivo de convidar a comunidade acadêmica a desbravar novos campos de conhecimento sobre o tema e contribuir para o avanço em pesquisas que explorem os desafios apontados nesta revisão.
ARGYRIS, C. Understanding organizational behavior. Homewood, IL: Dorsey Press, 1960.

ARNOLD, J. The psychological contract: a concept in need of closer scrutiny? European Journal of Work and Organizational Psychology, v.5, n.4, p.511-520, 1996. [DOI: 10.1080/13594329608414876].

CONWAY, N.; BRINER, R.B. Understanding psychological contracts at work: a critical evaluation of theory and research. New York: Oxford University Press, 2005. [DOI: 0.1093/acprof:0so/9780199280643.001.0001].

COYLE-SHAPIRO, J.; KESSLER, I. The psychological contract in the UK public sector: employer and employee obligations and contract fulfillment. In: HAVLOVIC, S.J. (Ed.). Academy of Management best paper proceedings. Briarcliff Manor, NH: Academy of Management, 1998. v.58, p.1-7.

COYLE-SHAPIRO, J.; KESSLER, I. Consequences of the psychological contract for the employment relationship: a large scale survey. Journal of Management Studies, v.37, n.7, p.903-930, Nov. 2000.

[DOI: 10.1111/1467-6486.00210].

DELCAMPO, R. Psychological contract violation: an individual difference perspective. International Journal of Management, v.24, n.1, p.43-52, Mar. 2007.

FOA, U.G.; FOA, E.B. Societal structures of the mind. Springfield, IL: Charles C. Thomas, 1974.

GUEST, D.E. Is the psychological contract worth taking serious? Journal of Organizational Behavior, v.19, Issue S1, p.649-664, 1998.

[DOI: 10.1002/(SICI)1099-1379(1998)19:1+<649::AID-JOB970>3.0.CO;2-T].

GUZZO, R.A.; NOONAN, K.A. Human resource practices as communications and the psychological contract. Human Resource Management Journal, v.33, n.3, p.447-462, 1994. [DOI: 10.1002/hrm.3930330311].

GUZZO, R.A; NOONAN, K.A.; ELRON, E. Expatriate managers and the psychological contract. Journal of Applied Psychology, v.79, p.617-626, 1994.

[DOI: 10.1037/0021-9010.79.4.617].

HERRIOT, P. New dealing. In: CITY UNIVERSITY CONFERENCE "THE NEW DEAL IN EMPLOYMENT", Dec. 1995, London. Paper presented at... London: City University, 1995.

HERRIOT, P.; MANNING, W.E.G.; KIDDER, J.M. The content of psychological contract. British Journal of Management, v.8, p.151-162, 1997. [DOI: 10.1111/1467-8551.0047].
Nesse sentido, é importante que as novas pesquisas tentem responder, ainda que parcialmente, os inúmeros questionamentos apontados por pesquisadores do tema, utilizando novas metodologias para o enriquecimento dos achados científicos.
HERRIOT, P.; PEMBERTON, C. Facilitating new deals. Human Resource Management Journal, v.7, p.45-56, 1997. [DOI: 10.1111/j.1748-8583.1997.tb00273.x].

HUI, C.; LEE, C.; ROUSSEAU, D.M. Psychological contract and organizational citizenship behavoir in China: investigating generalizability and instrumentality. Journal of Applied Psychology, v.89, n.2, p.311-321, 2004.

[DOI: 10.1037/0021-9010.89.2.311].

KICKUL, J.R.; LESTER, S.W.; FINK, J. Promise braking during radical organizational change: do justice interventions make difference? Journal of Organizational Behavior, v.23, issue 1, p.469-488, 2002.

[DOI: 10.1002/job.151].

KOTTER, J.P. The psychological contract: managing the joining up process. California Management Review, v.15, p.91-99, 1973.

[DOI: $10.2307 / 41164442]$.

LESTER, S.W.; TURNLEY, W.H.; BLOODGOOD, J.M.; BOLINO, M.C. Not seeing eye to eye: differences in supervisor and subordinate perceptions of and attributions for psychological contract breach. Journal of Organizational Behavior, v.23, p.30-56, 2002.

[DOI: 10.1002/job.126].

LEVINSON, H.; MANDL, H.J.; MUNDEN, K.J.; PRICE, C.R.; SOLLEY, C.M. Men, management and mental health. Cambridge, UK: Harvard University Press, 1963.

MACNEIL, I.R. Relational contract: what we do and do not know. Wisconsin Law Sociology Review, v.28, p.55-69, 1985.

MECKLER, M.; DRAKE, B.H.; LEVINSON, H. Putting psychology back into psychological contracts. Journal of Management Inquiry, v.12, p.217-228, Sept. 2003.

MENEGON, L.F. Contratos psicológicos como fatores influenciadores dos índices de rotatividade voluntária em empresas de consultoria. 2004. Dissertação (Mestrado) Faculdade de Economia, Administração e Contabilidade da Universidade de São Paulo, São Paulo, São Paulo, Brasil, 2004.

MENNINGER, K. Theory of psychoanalytic technique. 2nd ed. New York: Basic Books, 1958.

[DOI: 10.1037/10843-000].

MILLWARD, L.J.; HOPKINS, L.J. Psychological contracts, organizational and job commitment. Journal of Applied Social Psychology, v.28, n.16, p.1530-1556, 1958. [DOI: 10.1111/j.1559-1816.1998.tb01689.x].

MORRISON, E.W.; ROBINSON, S.L. When employees feel betrayed: a model of how psychological contract violations 
develops. Academy of Management Review, v.22, n.1, p.226-256, 1997.

[DOI: 10.5465/AMR.1997.9707180265].

PEYRAT-GUILLARD, D. Union discourse and perceived violation contract: a social contract-based approach. Industrial Relations, v.63, n.3, p.479-501, 2008.

RAJA, U.; JOHNS, G.; NTALIANIS, F. The impact of personality on psychological contracts. Academy of Management Journal, v.47, n.3, p.350-367, 2004. [DOI: 10.2307/20159586].

ROBINSON, S.L. Trust and breach of the psychological contract. Administrative Science Quaterly, v.41, p.574-599, 1996.

[DOI: 10.2307/2393868].

ROBINSON, S.L.; KRAATZ, M.S.; ROUSSSEAU, D.M. Changing obligations and the psychological contract: a longitudinal study. Academy of Management Journal, v.37, p.137-152, 1994.

[DOI: $10.2307 / 256773]$.

ROBINSON, S.L.; MORRISON, E.W. Psychological contracts and OCB: the effect of unfulfilled obligations on civic virtue behavior. Journal of Organizational Behavior, v.16, issue 3, p.289-298, 1995.

[DOI: 10.1002/job.4030160309].

ROBINSON, S.L.; ROUSSEAU, D.M. Violating the psychological contract: not the exception but the norm. Journal of Organizational Behavior, v.15, issue 3, p.245-259, 1994. [DOI: 10.1002/job.4030150306].

ROUSSEAU, D.M. Psychological and implied contracts in organizations. Employee Responsibilities and Rights Journal, v.2, p.121-139, 1989.

[DOI: 10.1007/BF01384942].

ROUSSEAU, D.M. New hire perceptions of their own and their employer's obligations: a study of psychological contracts. Journal of Organizational Behavior, v.11, issue 5, p.389-400, 1990. [DOI: 10.1002/job.4030110506].
ROUSSEAU, D.M. Psychological contracts: understanding written and unwritten agreements. Thousand Oaks, CA: Sage, 1995.

ROUSSEAU, D.M. The 'problem' of psychological contract considered. Journal of Organizational Behavior, v.19, issue S1, p.665-671, 1998.

[DOI: 10.1002/(SICI)1099-1379(1998)19:1+<665::AID-JOB972>3.0.CO;2-X].

ROUSSEAU, D.M. Psychological contract inventory: technical report. Version 3. Aug. 2000. Disponível em: <www.andrew.cmu.edu/user/rousseau>.

Acesso em: 10 out. 2009

ROUSSEAU, D.M.; PARKS, J.M. The contracts of individuals and organizations. Research in Organizational Behavior, v.15, p.1-43, 1993.

ROUSSEAU, D.M.; TIJORIWALA, S.A. Assessing psychological contracts: issues, alternatives and measures. Journal of Organizational Behavior, v.19, p.679-695, 1998. [DOI: 10.1002/(SICI)1099-1379(1998)19:1+<679::AID-JOB971>3.0.CO;2-N].

RUBERY, J.; EARNSHAW, J.; MARCHINGTON, M.; COOKE, F.L.; VINCENT, S. Changing organizational forms and the employment relationship. Journal of Management Studies, v.39, n.5, p.645-672, July 2002.

[DOI: 10.1111/1467-6486.00306].

SCHEIN, E.H. Organizational psychology. $3^{\text {rd }}$ ed.

Englewoods Cliffs, NJ: Prentice Hall, 1980. (Original work published 1965).

SHORE, L.M.; TETRICK, L.E. The psychological contract as an explanatory framework in the employment relationship. In: COOPER, C.L.; ROUSSEAU, D.M. Trends in organizational behavior. New York: Wiley, 1994. p.91-103.

SPINDLER, S.G. Psychological contracts in workplace: a lawer's view. Human Resource Management, v.33, n.3, p.325-334, Fall 1994.

[DOI: 10.1002/hrm.3930330303].

VROOM, V.H. Work and motivation. New York: Wiley, 1964.

\section{Psychological contracts: a review of the literature}

This paper discusses, through a review of the literature, the concept of psychological contracts and its importance for the understanding of labor relations, presenting their contents, categorization, key research studies and results in domestic and in international terms, to then present the challenges to be explored by future researchers of the subject.

Keywords: psychological contracts, breach and violation of psychological contracts, research challenges.

\section{Contratos psicológicos: una revisión de la literatura}

Este trabajo tiene por objetivo analizar, por medio de una revisión de la literatura, el concepto de contratos psicológicos y su importancia para la comprensión de las relaciones laborales. Se examinan su contenido, categorización, principales corrientes y resultados de investigaciones nacionales e internacionales. Se presentan, además, los retos a las futuras investigaciones sobre el tema.

Palabras clave: contrato psicológico, ruptura y violación del contrato psicológico, desafíos de investigación. 